\title{
Potential benefits of minimum unit pricing for alcohol versus a ban on below cost selling in England 2014: modelling study
}

\author{
(c) (1) (8) OPEN ACCESS
}

\begin{abstract}
Alan Brennan professor of health economics and decision modelling, Yang Meng research fellow, John Holmes research fellow, Daniel Hill-McManus research associate, Petra S Meier professor of public health
\end{abstract}

School of Health and Related Research (ScHARR), University of Sheffield, Sheffield S1 4DA, UK

\begin{abstract}
Objective To evaluate the potential impact of two alcohol control policies under consideration in England: banning below cost selling of alcohol and minimum unit pricing.
\end{abstract}

Design Modelling study using the Sheffield Alcohol Policy Model version 2.5 .

Setting England 2014-15.

Population Adults and young people aged 16 or more, including subgroups of moderate, hazardous, and harmful drinkers.

Interventions Policy to ban below cost selling, which means that the selling price to consumers could not be lower than tax payable on the product, compared with policies of minimum unit pricing at $£ 0.40$ ( $€ 0.57$; $\$ 0.75)$, 45p, and 50p per unit $(7.9 \mathrm{~g} / 10 \mathrm{~mL})$ of pure alcohol.

Main outcome measures Changes in mean consumption in terms of units of alcohol, drinkers' expenditure, and reductions in deaths, illnesses, admissions to hospital, and quality adjusted life years.

Results The proportion of the market affected is a key driver of impact, with just $0.7 \%$ of all units estimated to be sold below the duty plus value added tax threshold implied by a ban on below cost selling, compared with $23.2 \%$ of units for a $45 p$ minimum unit price. Below cost selling is estimated to reduce harmful drinkers' mean annual consumption by just $0.08 \%$, around 3 units per year, compared with $3.7 \%$ or 137 units per year for a $45 \mathrm{p}$ minimum unit price (an approximately 45 times greater effect). The ban on below cost selling has a small effect on population health-saving an estimated 14 deaths and 500 admissions to hospital per annum. In contrast, a $45 p$ minimum unit price is estimated to save 624 deaths and 23700 hospital admissions. Most of the harm reductions (for example, $89 \%$ of estimated deaths saved per annum) are estimated to occur in the $5.3 \%$ of people who are harmful drinkers.

Conclusions The ban on below cost selling, implemented in the England in May 2014, is estimated to have small effects on consumption and health harm. The previously announced policy of a minimum unit price, if set at expected levels between 40p and 50p per unit, is estimated to have an approximately 40-50 times greater effect.

\section{Introduction}

The UK government has been considering different policy options to regulate the price of alcohol in England and Wales. Increasing the price of alcohol has been shown to be effective in reducing both consumption levels ${ }^{1}$ and harms. ${ }^{2}$ Recent Canadian research shows that minimum pricing policies reduce total alcohol consumption, shift consumption away from high strength beverages, and reduce alcohol related admissions to hospital. ${ }^{34}$ In 2010, the UK government proposed a "ban on below cost selling," which would target drinks that are currently sold so cheaply that their price is below the cost of production and retail. ${ }^{5}$ In principle this would affect alcohol wherever sold, but in practice such cheap drinks are sold in supermarkets and other shops (the "off-trade") rather than in pubs, clubs, bars, and restaurants (the "on-trade"). In the absence of detailed, commercially sensitive information on production and retail costs, the government developed a simplified policy, which proposed that the selling price to consumers could not be lower than the tax payable on the product. In the United Kingdom, tax on alcohol has two components: the alcohol beverage specific duty, for example, $£ 28.22$ ( $€ 35.57 ; \$ 46.10$ ) per litre of pure alcohol for spirits as of March 2014, and a sales value added tax (VAT), which is currently an additional $20 \%$ on top of the price of the product. Thus the selling price for a product under a ban on below cost selling (BBCS) policy would not be allowed to be lower than Price $_{\mathrm{BBCS}}=$ duty+duty $\times 20 \%$. Because the alcohol duty rates vary for different drinks, a ban on below cost selling would target those drinks that currently have higher duty rates (for example, spirits) and have less effect on drinks 
with lower duty rates (for example, cider). In 2012 the UK government announced an alternative policy for its alcohol strategy - a minimum unit price for alcohol ${ }^{6}$ - and levels discussed ranged between 40p and 50p per unit. In 2013 the government then withdrew this commitment and returned to its previous ban on below cost selling policy, which it subsequently introduced in May 2014. ${ }^{7}$ Under a minimum unit price policy, the minimum selling price increases in proportion to the alcohol units contained in the drink ( 1 unit=7.9 $\mathrm{g} / 10 \mathrm{~mL}$ of pure ethanol). Thus a minimum unit price measure would target those drinks that are high in alcohol content and sold relatively cheaply; drinks that are favoured more by those drinking at harmful levels. ${ }^{8}$ For eight example purchases, table $1 \Downarrow$ shows that a ban on below cost selling thresholds would differ considerably compared with, for example, a $45 \mathrm{p}$ minimum unit price level, and that since the duty on cider is low and does not increase in line with alcohol content, the ban on below cost selling threshold falls as low as $6 \mathrm{p}$ per unit for high strength cider.

The potential effects of a minimum unit price in England were previously examined in 2009-10. ${ }^{89}$ The Sheffield Alcohol Policy Model (version 2.0) used consumption survey data from the general lifestyle survey 2006 as the baseline year. The model also included levels of purchasing and prices paid from the expenditure and food surveys 2001-06 and commercially available population level distributions for prices paid for various alcohol beverage types from the commercial market research companies CGA Strategy and AC Nielsen for 2008. Baseline levels of the harms associated with alcohol were taken from 2005 for admissions to hospital and mortality in 47 diseases. ${ }^{10}$ The model estimated changes in consumption and the levels of harms over a 10 year period after the introduction of the policy, examining 54 subgroups of the population based on age, sex, and three levels of consumption (moderate, hazardous, and harmful). The research report and subsequent publications examined the potential impact of a minimum unit price threshold, ranging from $20 \mathrm{p}$ to $70 \mathrm{p} \mathrm{per} \mathrm{unit.}{ }^{8}$ The findings contributed substantially to the debate surrounding pricing regulation and future policy options. ${ }^{11}{ }^{12}$ Several areas were identified for further development of both the version 2.0 model and the evidence used within it. In particular, further evidence and analyses on the price elasticities for alcohol (which are used to quantify the relation between price changes and consumption changes) were a priority. The original work used cross sectional analysis of five years of data from the expenditure and food survey to estimate price elasticities for the main analysis, and also tested how sensitive the results were to alternative estimates taken from the research literature. The previous model combined beers and ciders, which would be better separated given their different duty rates and consumption patterns.

We defined moderate drinking as alcohol intake up to 21 units per week for males and 14 units per week for females, and non-drinkers were included in this group; hazardous drinking as alcohol intake between 21 and 50 units per week for males and between 14 and 35 units for females; and harmful drinking as alcohol intake of more than 50 units per week for males and over 35 units for females.

In this study we have developed a new version of the Sheffield Alcohol Policy Model (version 2.5) in which we have updated data on baseline consumption and prices; developed new estimates on price elasticity accounting for the longitudinal aspects of the expenditure and food survey data (now renamed as the living costs and food survey), separated cider from beers; and incorporated greater subgroup functionality including the ability to define socioeconomic subgroups. ${ }^{13}$ The Sheffield
Alcohol Policy Model (version 2.5) is used to address the current research question: What would be the differential potential impact of a ban on below cost selling versus a minimum unit price policy of 40p, 45p, or 50p if the policies were to be implemented in 2014-15? In particular, what are the estimated potential effects on alcohol consumption, consumer spending, tax and duty revenues, and health harms, including deaths, admissions to hospital, quality of life, and costs to the National Health Service of these outcomes?

\section{Methods \\ Overview of the model}

The aim of Sheffield Alcohol Policy Model (version 2.5) is to appraise a wide variety of policy options, including minimum unit pricing through analysis of selected costs and benefits. This involves modelling a linked series of policy outcomes for 96 population subgroups defined by sex, age, annual income, and consumption level. The outcomes are: the effect of the policy on the distribution of prices for different types of alcohol; the effect of changes in price on alcohol consumption; the effect of changes in alcohol consumption on revenue for retailers, the exchequer, and consumer spending on alcohol; and the effect of changes in alcohol consumption on levels of alcohol related admissions to hospital and deaths and quality adjusted life years lost. The model also appraises effects on crime and workplace outcomes (not reported here). The methods used are set out below (see supplementary technical appendix for full details).

\section{Baseline data}

The modelling begins with individual level baseline data from the general lifestyle survey 2009 on mean weekly and peak day consumption (a proxy for individuals' scale of binge drinking) of alcohol for 11385 people in England. It considers 96 subgroups split by age, sex, mean consumption level (moderate, hazardous, and harmful), and income (low and higher income). (We define low income as those below the relative poverty line, defined as $60 \%$ of median equivalised household income and higher income as people above the relative poverty line.) Data on prices paid and quantity purchased by each subgroup for 10 different beverage types (off-trade and on-trade beer, cider, wine, spirits, and ready to drinks "alcopops") are available from the living costs and food survey, an annual two week purchasing diary survey of around 6500 UK households. We utilised data on prices paid for England only, for the years 2001-02 to 2009, a sample of 227933 purchasing transactions. These self reported prices paid for alcohol are known to over-estimate the mean price paid, ${ }^{9}$ and we adjust them so that the distribution of actual amounts of alcohol bought at different price levels match with actual sales prices in the market using 2011 data from AC Nielsen and CGA Strategy.

\section{Process for estimating effect of price change on consumption for population subgroups}

A minimum unit price or a ban on below cost selling policy is assumed to increase all product prices below the policy threshold up to exactly the threshold level, and it is further assumed to affect none of the products currently priced above the threshold. The percentage change in mean price paid in each subgroup for the 10 beverage types is used to estimate the effect of price changes on consumption. This is done in conjunction with own price elasticities (for example, percentage change in consumption of off-trade beer given a $1 \%$ increase in off-trade beer price), and cross price elasticities (for example, percentage change in off-trade beer consumption given a $1 \%$ increase in 
the price of another product, for example, off-trade spirits). When a change in prices is inputted as a model scenario, the percentage change in mean weekly consumption for each population subgroup is estimated for each beverage. This is then applied to the corresponding individual level consumption data in the model. Each individual's percentage change in peak daily consumption is indirectly modelled using a linear regression, with peak daily consumption estimated as a function of mean weekly consumption, age, and sex.

\section{Estimating price elasticities for alcohol}

To estimate the effect of changing prices on consumption, a new set of price elasticity models have been developed. Full details on the statistical approach and the model fit can be found elsewhere. ${ }^{14}$ Technically, we used individual level data from the living costs and food survey for 2001 to 2009 to construct a time series pseudopanel for 72 defined population groups based on sex, birth year, and socioeconomic status. Within each population group, in each year, and for each of the 10 beverage categories, we calculated the mean number of units purchased and the mean price paid. A set of 10 fixed effects regression models were then fitted to estimate the own and cross price elasticities. Covariates adjusted for in the final models were income, age, and proportions of individuals in each population group having children, and being married, unemployed, and a smoker. Table $2 \Downarrow$ shows the resulting own price and cross price elasticities. To illustrate the interpretation, the own price elasticity for off-trade beer (top left cell of matrix) was -0.980 , which means that a $1 \%$ increase in the price of off-trade beer would be estimated to result in a $0.98 \%$ reduction in the amount purchased. Similarly, there can be switching between drinks when prices change, so for example (two cells to the right), a $1 \%$ increase in off-trade beer was estimated to produce a slight increase of $0.096 \%$ in purchasing of off-trade wine. To examine the effects of uncertainty, we also carried out runs of the Sheffield Alcohol Policy Model (version 2.5) using alternative definitions to generate the pseudopanel purchasing groups, and using probabilistic sensitivity analysis accounting for variable uncertainty reported in the regression coefficients. ${ }^{15} 16$

Note that different subgroups in Sheffield Alcohol Policy Model (version 2.5) experience different scales of effect due to a price change because for each subgroup we accounted for data on their preferences for the 10 categories of beverage (for example, middle aged women drink more wine at home, younger men drink more beer on nights out) and data on the prices paid for each of the 10 beverages (for example, harmful drinkers spend less per unit on average). Thus, the $10 \times 10$ matrix of price elasticities means that each of the 96 modelled population subgroups essentially has a different overall price elasticity and a different scale of response to a given policy (for example, drinkers who favour cheaper cider would be more affected by a minimum unit price because their beverages would experience a relatively large increase in price and also because the own price elasticity for off-trade cider is relatively large at -1.268 ).

\section{Risk functions and modelling process for health harms}

The baseline and estimated post-policy consumption data for each of the population subgroups feed into a second model component relating changes in consumption to changes in harm. We model the effects of consumption changes on mortality and disease prevalence for 47 conditions defined by the international classification of diseases, 10th revision (ICD-10) codes. ${ }^{10}$ The modelling uses epidemiological risk functions, which one can visualise as a graph, with the $\mathrm{x}$ axis being level of consumption of alcohol in units and the y axis being the risk of harm, for example, relative risk of mortality from oesophageal cancer (ICD10 code C15). We partitioned the diseases into four categories: chronic or acute conditions, which were attributable partially or wholly to alcohol. For partially attributable chronic conditions, we used functions relating an individual's mean consumption to his or her health risk from the published literature. ${ }^{15}$ For partially attributable acute conditions, published literature is more limited, and we quantified functions relating highest daily consumption to risk by calibrating the slope of an assumed linear risk function to published evidence of the alcohol attributable fractions for each condition (see details ${ }^{8}$ ). For wholly attributable chronic and acute conditions, we similarly calibrated functions relating either mean weekly units or maximum daily consumption to absolute risk to published evidence on the absolute number of cases observed. ${ }^{8}$

This process was undertaken both for annual mortality risk for each condition and for morbidity risk, where morbidity was defined as the annual rate of person specific admissions to hospital. Condition specific mortality rates for each age and sex based subgroup are taken from published analyses of 2005-06 Office for National Statistics, and morbidity rates from 2005-06 hospital episodes statistics. ${ }^{10}$

The modelled change in consumption for each subgroup then feeds into a change in relative or absolute risk, and the potential impact fraction method ${ }^{17}$ is used to adjust observed mortality and morbidity rates. For chronic conditions, there can be a time lag between population level changes in alcohol consumption and changes in outcome, and we chose a linear time lag function of 10 years to realisation of full effect, which is consistent with average estimates in the literature. ${ }^{18}$

\section{Framework for base case and sensitivity analyses}

For all ban on below cost selling analyses, we estimated the average duty plus VAT per unit of alcohol for beer, cider, wine, spirits, and ready to drink beverages (or alcopops) in the United Kingdom based on the duty rates set by Her Majesty's Revenue and Customs effective from 25 March 2013. We used several assumptions to estimate these thresholds because different duty rates exist for the same modelled beverage type (for example, there are currently three duty rates for beer which increase with alcohol content) and because duty rates for cider and wine are calculated based on product volume rather than on ethanol content. (For full details see supplementary technical appendix table 13.1 or table 1 in Meng et $\mathrm{al}^{16}$.)

The set of policies analysed are a ban on below cost selling and minimum unit price polices with thresholds of 40p, 45p, and $50 p$ in $2014-15$ prices. We particularly focus on $45 p$ as this was the level proposed by the UK government. The model actually uses 2011 as the baseline year because this is our most recently availably price distribution data. We adjusted for future beverage specific retail price indices using estimates provided by the Home Office (for details see supplementary technical Appendix table 5.3).

The analysis reported here applies the elasticity matrix estimated in table 2. See online for the full details on methods and results of sensitivity analyses undertaken to test the robustness of our results under alternative elasticity matrices (for example, assuming no substitution effects, excluding non-significant $(\mathrm{P}<0.05)$ elasticities, separate matrices for low income and higher income groups, and separate matrices for moderate versus hazardous or harmful groups). ${ }^{16}$ 


\section{Results}

The proportion of the market that would be affected by price regulation is the key driver of the scale of estimated policy impact. Overall, just $0.7 \%$ of alcohol units are estimated to be sold below the ban on below cost selling duty plus VAT threshold. In contrast, a $45 \mathrm{p}$ minimum unit price would affect $23.2 \%$ of all units. For analyses across subgroups, baseline consumption and prices paid are shown in table $3 \Downarrow$. Harmful drinkers are a policy priority group, as they consume substantially (on average 58 units per week for females, 80 units for males) and spend substantially ( $£ 1800$ and $£ 3400$ per annum, respectively). Of the population aged 16 or more, 2.2 million $(5.3 \%)$ are harmful drinkers, 7.2 million $(17.3 \%)$ are hazardous drinkers, and 25.5 million $(61.5 \%)$ are moderate drinkers. The proportion of alcohol affected by a minimum unit price varied across these subgroups: for example, a $45 \mathrm{p}$ minimum unit price would affect $12.5 \%, 19.5 \%$, and $30.5 \%$ of units sold to moderate, hazardous, and harmful drinkers, respectively. In contrast, table 3 and figure $1 \Downarrow$ show that the impact of a ban on below cost selling on all drinkers would be minimal, and just $1.0 \%$ of units currently consumed by harmful drinkers would be affected.

Table $4 \Downarrow$ shows the estimated impact on consumption and on spending for subgroups. A ban on below cost selling was estimated to reduce harmful drinkers' mean annual consumption by around 3 units (approximately 1.5 fewer pints of beer in a year). In contrast, a $45 \mathrm{p}$ minimum unit price was estimated to reduce harmful drinkers' consumption by 137 units per year; an approximately 45 times greater effect than a ban on below cost selling. Changes in spending were relatively small for all subgroups under a $45 \mathrm{p}$ minimum unit price. This is because several price elasticity estimates for beverage types particularly affected by these policies (see table 2) are around -1.000 , indicating that as people face increased prices for these products they reduce purchasing to an extent that maintains their current level of spending. Thus, for example, although harmful drinkers were estimated to reduce mean annual consumption by 137 units, because the products that they buy would now have higher prices mean spending was estimated to change for this subgroup by just minus $£ 1.70$ per year $(0.06 \%$ of the $£ 2771$ total). For a $45 \mathrm{p}$ minimum unit price, moderate drinkers on average were barely affected in terms of both mean consumption and mean spending (a reduction of 1.6 units-less than one pint of beer per annum and an increase in spending per annum of 90p).

Figure $2 \Downarrow$ illustrates the 45 -fold greater effectiveness of a $45 p$ minimum unit price over a ban on below cost selling in terms of reductions in consumption.

The estimates for reduction in health harm again show that a ban on below cost selling has minimal effect (table $5 \Downarrow$ ). For example, 10 years after policy implementation, the ban on below cost selling showed a saving of just 14 deaths and around 500 admissions to hospital per annum, which compared with an estimated 624 deaths and 23700 admissions prevented by a $45 p$ minimum unit price-around a 40 to 50 times greater effect than a ban on below cost selling. A similar pattern was shown for the cumulative measures of harm reduction over 10 years, which were each almost 50 times higher for a $45 p$ minimum unit price versus a ban on below cost selling-for example, total quality adjusted life year (QALY) gains for England (24 $200 v$ $500)$, healthcare cost savings (-£9.5m $v-£ 417.2 \mathrm{~m})$, and the financial valuation of the QALY gains assuming a $£ 60000$ value for one quality adjusted life year in line with Department for Health guidance ( $£ 33 \mathrm{~m} v £ 1591$ ). Most of the harm reduction occurred in those $5.3 \%$ of people who were harmful drinkers (for example, for a $45 \mathrm{p}$ minimum unit price, 554 of the 624 deaths equated to $89 \%$ of the estimated overall death reduction). Figure $3 \Downarrow$ illustrates the 40 -fold difference between harm reduction estimates for a $45 \mathrm{p}$ minimum unit price and those for a ban on below cost selling, and also shows that as the threshold of alternative values for a minimum unit price was increased (for example, 40p, 45p, 50p), thus covering more of the market of products, then the estimated harm reductions increased.

The wider economic effects on retailer revenues and tax revenues have also been examined. In summary, retailer revenues in shops and supermarkets (the off-trade) for a $45 p$ minimum unit price are estimated to increase by $5.6 \%$ or $£ 201.1 \mathrm{~m}$ while for a ban on below cost selling the effects are small: a $0.2 \%$ or $£ 5.4 \mathrm{~m}$ increase. One would expect that this increase in revenues would imply an increase in profits on alcohol sales for off-trade retailers but, without access to the details of retailers' cost base, a quantified calculation of profits cannot be undertaken. In contrast, the effects on government tax revenue are small, primarily because the two separate tax effects counteract each other. Alcohol duty revenue will fall a little because it is related to the volume of alcohol sold, but VAT will rise a little because it is charged as a percentage of product price and products are being sold at higher prices. The net effect was estimated at decreased total alcohol tax revenues of $£ 48.5 \mathrm{~m}$ or $0.6 \%$ for a $45 \mathrm{p}$ minimum unit price and $£ 1.5 \mathrm{~m}$ or $0.02 \%$ for a ban on below cost selling.

Several sensitivity analyses have been undertaken on these central estimates to consider uncertainty. Details of all of these are provided in the report sent to the UK Home Office to inform its responses to a consultation on minimum unit pricing, which can be seen online..$^{15}$ The results support the above findings on the comparative effectiveness of a ban on below cost selling and a minimum unit price but suggest that the base case minimum unit price model may be conservative in its estimates of policy effectiveness.

\section{Discussion}

This study quantifies the potential impact of the UK government's policy of a ban on selling alcohol for less than the cost of the payable duty and VAT using the Sheffield Alcohol Policy Model (version 2.5) to estimate the proportion of products affected, the reduced consumption of alcohol by different population subgroups, and the resulting harm reductions. The findings suggest that the effects of a ban on below cost selling would be small-a $-0.04 \%$ change in consumption and a central estimate for the reduction in deaths of just 14 per year at full effect. We have compared this with the minimum unit price policy originally proposed by the prime minister in the government's alcohol strategy ${ }^{6}$ and find that such a policy would have an estimated 40-50-fold greater effect than a ban on below cost selling. Sensitivity analyses on these effects suggest that the relative scale of impact between a ban on below cost selling and a minimum unit price are robust to a variety of assumptions and uncertainties.

The study has also examined subgroup impacts, showing that the greatest effects of a $45 \mathrm{p}$ minimum unit price policy would be in harmful drinkers. This is because they are the group that buys the greatest share of the cheaply priced alcohol, faces greater price increases than for example moderate drinkers if a $45 \mathrm{p}$ minimum unit price were implemented, and buys in larger volumes thus incurring larger absolute reductions in consumption leading to larger harm reductions. For a $45 p$ minimum unit price, they are estimated to reduce consumption by 137 units per year on average and gain in terms of an estimated reduced mortality rate of 550 fewer deaths per year. 
In contrast, the $61.5 \%$ of the population who are moderate drinkers are on average affected little - a mean reduction in consumption of 1.6 units per year and spending increase of just $90 \mathrm{p}$ per year for a $45 \mathrm{p}$ minimum unit price.

\section{Strengths and weaknesses of this study}

Our study has several limitations in relation to the evidence base available. Self report surveys can be problematic for under-recording alcohol consumption (general lifestyle survey) and purchasing (living costs and food survey), which will affect the results for change in consumption and spending. ${ }^{19}$

Potentially, under-recording could also affect the estimation of harm reduction; although this is less clear because there is debate on whether surveys underpinning the risk function literature measure exposure to alcohol in a way that is consistent with our surveys or otherwise..$^{20}$ In the absence of a single dataset recording both purchase and consumption, the model assumes that a $1 \%$ change in purchasing by an individual equates to a $1 \%$ change in consumption, although with a ban on below cost selling effect of $-0.04 \%$, plausible alternative assumptions would make a negligible difference. The measure of binge drinking available in the general lifestyle survey (consumption on the peak drinking day in the seven days before the survey) also has limitations, and we are beginning to explore the use of more refined measures of binge behaviour, including frequency of drinking occasions and level of consumption on each occasion..$^{21}$ Evidence shows that the relation between consumption and health risk may differ for mortality compared with morbidity for some conditions. ${ }^{22}$ However, as such evidence is not available for all conditions, we do not model separate mortality and morbidity risk relations, although this would be possible as the evidence base develops. Price elasticities are also an important driver of the results and, although we have further improved our price elasticity estimates in this version of the model, the ideal data, a longitudinal population panel collecting both prices paid and amounts consumed for the various categories of alcohol, is not available in the United Kingdom (see details in Meng et $\mathrm{al}^{14}$ ). The model as it stands is valid when comparing the differences between two pricing policies. In quantifying these differences it makes the assumption that, all other things being equal, the patterns of population consumption would remain as they are currently evidenced in the most recent baseline year, rather than having a dynamic long term trend analysis. This means that the model provides an estimate of the incremental difference between "with minimum unit price policy" and "without minimum unit price policy" but does not directly account for concurrent effects of other policies or societal trends on any of the outcome measures used. For example, the model results are not adjusted for trends in macroeconomic factors affecting alcohol affordability, such as changes in incomes or changes in macroeconomic growth, nor are they adjusted for the effects of other alcohol policy interventions operating simultaneously, such as increased use of screening and brief interventions, which we have previously estimated to be cost effective. ${ }^{23}$

\section{Strengths and weaknesses in relation to other studies}

This study has several strengths in relation to our own previously published work, which addresses minimum unit pricing but not a ban on below cost selling. ${ }^{8}$ We have extended the categories of alcoholic beverages to separate out cider, which has a different duty regimen, and this was an important development to allow more robust analysis of a ban on below cost selling. We have updated the data on consumption to 2009. We have recalibrated the relevant disease risk functions. We have updated prices paid using both new living costs and food survey and data from the commercial market research companies AC Nielsen and CGA Strategy for the years 2009 and 2011, respectively. Most importantly, rather than analysing the data on prices paid in a purely cross sectional manner we have generated new estimates of price elasticity effects, which incorporate a degree of longitudinality into the analysis.

Considering that the pricing policies being discussed here have either never been implemented in the United Kingdom or have only recently been implemented, there is currently a lack of data with which to validate our findings. However, we have also applied these methods to two Canadian provinces, ${ }^{24}$ the results of which can be compared with external data. Ontario and British Columbia have both government liquor stores and an extensive network of private liquor stores, which are required to comply with minimum price regulations for each beverage type. We applied the Sheffield Alcohol Policy Model (version 2.0) framework to these provinces, using Canadian data on alcohol consumption, alcohol purchasing, and rates of harm. We compared Sheffield Alcohol Policy Model estimates to those obtained from statistical analyses of prices, health outcomes, and hospital admissions in British Columbia between 2002 and 2009. ${ }^{35}$ The estimates obtained using the Sheffield Alcohol Policy Model (version 2.0) approach seem to be conservative compared with actual results, with estimates typically less than half those from the statistical modelling. This is consistent with our approach of, where necessary, making conservative assumptions so as not to overstate the potential impact of minimum unit pricing policies. For example, the assumption that higher priced products are not affected by setting a minimum unit price may be conservative, and Canadian evidence from British Columbia has found that when minimum prices were raised, the prices of some more costly beverages also increased. ${ }^{4}$ A second example relates to evidence that is also emerging in Canada whereby the assumption of a lag function of 10 years to realise a full effect on chronic disease outcomes may also be conservative because statistically significant impacts on alcohol related disease have been found between two and four years after prices changed..$^{25}$

\section{Meaning of the study: possible explanations and implications for clinicians and policymakers}

The reasons why the Sheffield Alcohol Policy Model (version 2.5 ) estimates a $45 \mathrm{p}$ minimum unit price has such greater estimated impact than a ban on below cost selling are clear-a greater proportion of the market is affected and to a greater extent and this is especially true for harmful drinkers. It is this more specific targeting of harmful drinkers that sets the minimum unit pricing policies aside from for example general price or tax increases across the board. From a national policy perspective, the UK government has recently implemented the ban on below cost selling but has indicated that it will watch with interest events in Scotland. The Scottish government passed legislation to introduce a $50 \mathrm{p}$ minimum unit price after reviewing analyses using the Sheffield Alcohol Policy Model (version 2.0 ${ }^{26}$, but has not been able to implement the policy owing to a legal challenge from the Scotch Whisky Association. The Republic of Ireland has also committed to introducing a similar policy in conjunction with Northern Ireland. More locally in the United Kingdom, several local authorities are considering or have enacted forms of price agreements or voluntary restrictions on sale of high strength low cost alcohol with local retailers, ${ }^{27}$ and this study suggests that agreements focusing 
on alcohol sold at 40p, 45p, or 50p per unit could have substantive effects in relation to drinker related harms.

\section{Unanswered questions and future research}

A key unanswered question is the relative effectiveness of minimum unit pricing when compared with general increases in tax. It would be of great interest and value to decision makers to analyse the comparative effects of further pricing policy options by, for example, quantifying the scale of increase in excise duty necessary to have equivalent consumption or harm reductions as those modelled here for a $45 \mathrm{p}$ minimum unit price, and to investigate what the impact of such duty increases would be on moderate drinkers. To do so requires analysis of duty rates and also the extent to which tax rises are passed on to consumers by retailers after they are implemented by government. ${ }^{29}$ This tax pass-through and comparative analysis is a topic of our ongoing research.

In addition to our analysis of health harms as described in this paper, a wider public health perspective can be used, and estimates are also available on the effects of these policies in terms of reductions in crime and absence from work. Beyond these policy research questions at national and local level, methodological issues remain around estimating the joint impact of price policies implemented alongside other interventions and services such as screening and brief interventions or specialist treatment services for dependent drinkers; the financial valuation of harms; and quantifying the harms done to others (for example, in families) rather than to drinkers themselves.

\section{Conclusion}

The UK government's recently implemented ban on below cost selling affects just $0.7 \%$ of alcohol units currently sold and is estimated to have small effects on consumption and health harm. The previously considered policy of a minimum unit price, if set at expected levels between 40p and 50p per unit, is estimated to have an approximately 40-50 times greater effect.

Contributors: $A B$ supervised the design and conduct of the modelling and drafted and finalised the manuscript. He is the guarantor. YM undertook the modelling work and led the development of version 2.5. $\mathrm{JH}$ contributed to the design of the modelling and drafting and revising the manuscript. DH contributed to the development of the modelling and drafting and revising the manuscript. PM is the principal investigator of the study and contributed to the design of the modelling and revision of the manuscript. All authors, external and internal, had full access to all of the data (including statistical reports and tables) in the study and can take responsibility for the integrity of the data and the accuracy of the data analysis. Independence of researchers: Researchers worked independently from the funders. Similarly the writing of the report and the decision to submit the article for publication was entirely independent of the funders.

Funding: The study was funded from a grant secured by the University of Sheffield from the Medical Research Council and Economic and Social Research Council, UK (No G1000043). The analysis was independently designed and undertaken by the School of Health and Related Research and collaborators. The study funder has no input into the design, analysis, or interpretation of data.

Competing interests: All authors have completed the ICMJE uniform disclosure form at www.icmje.org/coi_disclosure.pdf (available on request from the corresponding author) and declare: no support from any organisation for the submitted work except for funding as described above. no financial relationships with any organisations that might have an interest in the submitted work in the previous three years; no other relationships or activities that could appear to have influenced the submitted work.

Ethical approval: No ethics committee approval was required for this work as it consists of secondary analysis of data collected by third parties. All data on human participants was collected by UK government bodies under their own ethical procedures, and these cover using the data for purposes such as the present study.

Data sharing: The secondary data sources are already publicly available. Transparency: The lead author (AB) affirms that the manuscript is an honest, accurate, and transparent account of the study being reported; that no important aspects of the study have been omitted; and that any discrepancies from the study as planned have been explained.

1 Wagenaar AC, Salois MJ, Komro KA. Effects of beverage alcohol price and tax levels on drinking: a meta-analysis of 1003 estimates from 112 studies. Addiction 2009;104:179-90. Wagenaar AC, Tobler AL, Komro KA. Effects of alcohol tax and price policies on morbidity and mortality: a systematic review. Am J Public Health 2010;100:2270-8.

3 Stockwell T, Zhao J, Martin G, Macdonald S, Vallance K, Treno A, et al. Minimum alcohol prices and outlet densities in British Columbia, Canada: estimated impacts on alcohol-attributable hospital admissions. Am J Public Health 2013;103:2014-20.

4 Stockwell T, Auld MC, Zhao JH, Martin G. Does minimum pricing reduce alcoho consumption? The experience of a Canadian province. Addiction 2011:107:912-20.

5 HM Government. The coalition: our programme for government. Cabinet Office, 2010.

6 HM Government. The government's alcohol strategy. Cm 8336. Stationery Office, 2012. Home Office. Next steps following the consultation on delivering the government's alcoho strategy. 2013 www.gov.uk/government/uploads/system/uploads/attachment_data/file/ 223773/Alcohol_consultation_response_report_v3.pdf.

8 Purshouse RC, Meier PS, Brennan A, Taylor KB, Rafia R. Estimated effect of alcohol pricing policies on health and health economic outcomes in England: an epidemiological model. Lancet 2010;375:1355-64.

9 Purshouse RC, Brennan A, Latimer N, Meng Y, Rafia R, Jackson R. Modelling to assess the effectiveness and cost-effectiveness of public health related strategies and interventions to reduce alcohol attributable harm in England using the Sheffield Alcohol Policy Model version 2.0: Report to the NICE Public Health Programme Development Group. 2009. University of Sheffield.

10 Jones L, Bellis MA, Dedman D, Sumnall H, Tocque K. Alcohol-attributable fractions for England: alcohol-attributable mortality and hospital admissions. 2008. Liverpool John Moores University, Centre for Public Health.. www.nwph.net/nwpho/publications/ alcoholattributablefractions.pdf.

11 National Institute for Health and Care Excellence. Alcohol-use disorders: preventing harmful drinking. 2010. NICE public health guidance 24. www.nice.org.uk/Guidance/PH24/ Evidence.

12 House of Commons Health Committee. Government's alcohol strategy: Third reports of session 2012-13. 2012. Stationery Office.

13 Holmes J, Meng Y, Meier PS, Brennan A, Angus C, Campbell-Burton CA, et al. Effects of minimum unit pricing for alcohol on different income and socioeconomic groups: a modelling study. Lancet 2014;383:1655-64.

14 Meng Y, Brennan A, Purshouse R, Hill-MacManus D, Angus C, Holmes J, et al. Estimation of own and cross price elasticities of alcohol demand in the UK: a pseudo-panel approach using the Living Costs and Food Survey 2001-2009. J Health Econ 2014;34:96-103.

15 Meng Y, Brennan A, Holmes J, Hill-MacManus D, Angus C, Purshouse R, et al. Modelled income group-specific impacts of alcohol minimum unit pricing in England 2014/15: policy appraisals using new developments to the Sheffield Alcohol Policy Model (v2.5). 2013. ScHARR, University of Sheffield. www.sheffield.ac.uk/polopoly_fs/1.291621!/file/julyreport. pdf.

16 Meng Y, Brennan A, Holmes J, Hill-Mcmanus D, Angus C, Purshouse R, et al. Modelled income group-specific impacts of alcohol minimum unit pricing in England 2014/15: policy appraisals using new developments to the Sheffield Alcohol Policy Model (v2.5): addendum examining the impact of a ban on 'below cost selling'. 2013. ScHARR, University of Sheffield. www.shef.ac.uk/polopoly_fs/1.291630!/file/Addendum.pdf.

17 Gunning-Schepers $L$. The health benefits of prevention: a simulation approach. Health Policy 1989;12(1-2):1-255.

18 Holmes J, Meier PS, Booth A, Guo Y, Brennan A. The temporal relationship between per capita alcohol consumption and harm: a systematic review of time lag specifications in aggregate time series analyses. Drug Alcohol Depen 2011;123:7-14.

19 Meier PS, Meng Y, Holmes J, Baumberg B, Purshouse R, Hill-MacManus D, et al. Adjusting for unrecorded consumption in survey and per capita sales data: quantification of impact on gender- and age-specific alcohol attributable fractions for oral and pharyngeal cancers in Great Britain. Alcohol Alcohol 2013;48:241-9.

20 Rehm J, Kehoe T, Gmel G, Stinson F, Grant B, Gmel G. Statistical modeling of volume of alcohol exposure for epidemiological studies of population health: the US example. Popul Health Metr 2010;8:3.

21 Hill-MacManus D, Angus C, Meng Y, Holmes J, Brennan A, Meier P. Estimation of usual occasion-based individual drinking patterns using diary data. Drug Alcohol Depen 2013;134:136-43.

22 Rehm J, Taylor B, Mohapatra S, Irving H, Baliunas D, Patra J, et al. Alcohol as a risk factor for liver cirrhosis: a systematic review and meta-analysis. Drug Alcohol Rev 2010;29:437-45.

23 Purshouse R, Brennan A, Rafia R, Latimer N, Archer R, Angus C, et al. Modelling the cost-effectiveness of alcohol screening and brief interventions in primary care in England. Alcohol Alcohol 2012;48:180-8.

24 Hill-MacManus D, Brennan A, Stockwell T, Giesbrecht N, Thomas G, Zhao J, et al. Model-based appraisal of alcohol minimum pricing in Ontario and British Columbia: a Canadian adaptation of the Sheffield Alcohol Policy Model Version 2. 2012. University of Sheffield. www.carbc.ca/Portals/0/propertyagent/558/files/240/alcminpricingontbc.pdf.

25 Zhao J, Stockwell T, Martin G, Macdonald S, Vallance K, Treno A, et al. The relationship between minimum alcohol prices, outlet densities and alcohol attributable deaths in British Columbia 2002 to 2009. Addiction 2013;108:1059-69. 


\section{What is already known on this topic}

2010 analyses showed the estimated impact of different possible thresholds for a minimum unit price for alcohol in England and found that higher thresholds would lead to greater estimated reductions in harm

Canadian research has shown empirical evidence for direct impacts on health outcomes when minimum unit prices are increased

That research also suggests that the Sheffield Alcohol Model provides conservative estimates of harm reductions

\section{What this study adds}

The proportion of the market affected by the two policies differs hugely, with just $0.7 \%$ of all alcohol units sold likely to be affected under a ban on below cost selling compared with $23.2 \%$ of units for a $45 \mathrm{p}$ minimum unit price

Below cost selling would save an estimated 14 deaths and 500 admissions to hospital annually, compared with 624 deaths and 23700 admissions for a $45 \mathrm{p}$ minimum unit price

This study found very small estimated effects for banning below cost selling and showed, in comparison, that a minimum unit price of $45 p$ would be expected to have 40-50 times larger reductions in consumption and health harms

26 Meng Y, Hill-MacManus D, Brennan A, Meier P. Model-based appraisal of alcohol minimum pricing and off-licensed trade discount bans in Scotland using the Sheffield Alcohol Policy Model ( $v$ 2): second update based on newly available data. 2012. ScHARR, University of Sheffield. 2014. www.sheffield.ac.uk/polopoly_fs/1.150021!/file/scotlandupdatejan2012. pdf.

27 BBC. Ipswich super-strength alcohol drink campaign hailed a success. 2013. www.bbc. co.uk/news/uk-england-suffolk-24274991.

28 The Publican's Morning Advertiser. Newcastle council introduces alcohol minimum pricing 2013. www.morningadvertiser.co.uk/General-News/Newcastle-council-introduces-alcoholminimum-pricing.

29 Ally AK, Meng Y, Chakroborty R, Dobson PW, Seaton JS, Holmes J, et al. Alcohol tax pass-through across the product and price range: do retailers treat cheap alcohol differently? Addiction 2014; published online 24 Jun.

\section{Accepted: 22 August 2014}

\section{Cite this as: BMJ 2014;349:95452}

This is an Open Access article distributed in accordance with the Creative Commons Attribution Non Commercial (CC BY-NC 3.0) license, which permits others to distribute, remix, adapt, build upon this work non-commercially, and license their derivative works on different terms, provided the original work is properly cited and the use is non-commercial. See: http://creativecommons.org/licenses/by-nc/3.0/. 


\section{Tables}

Table 1| Example prices for different product categories under a ban on below cost selling compared with minimum unit pricing

\begin{tabular}{|c|c|c|c|c|c|c|c|c|}
\hline & \multicolumn{8}{|c|}{ Product (duty category) } \\
\hline & $\begin{array}{l}4 \times 440 \mathrm{~mL} \text { cans } \\
\text { of beer (normal } \\
\text { strength beer) }\end{array}$ & $\begin{array}{c}4 \times 440 \mathrm{~mL} \text { cans } \\
\text { of strong beer } \\
\text { (high strength } \\
\text { beer) }\end{array}$ & $\begin{array}{c}4 \times 440 \mathrm{~mL} \text { cans } \\
\text { of cider } \\
\text { (normal } \\
\text { strength cider) }\end{array}$ & $\begin{array}{l}2 \mathrm{~L} \text { bottle of } \\
\text { strong cider } \\
\text { (threshold } \\
\text { strength for } \\
\text { normal strength } \\
\quad \text { cider) }\end{array}$ & $\begin{array}{l}750 \mathrm{~mL} \text { bottle } \\
\text { of white wine } \\
\text { (wine) }\end{array}$ & $\begin{array}{l}750 \mathrm{~mL} \text { bottle } \\
\text { of red wine } \\
\text { (wine) }\end{array}$ & $\begin{array}{l}700 \mathrm{~mL} \text { bottle } \\
\text { of vodka } \\
\text { (spirits) }\end{array}$ & $\begin{array}{c}4 \times 175 \mathrm{~mL} \\
\text { bottles of ready } \\
\text { to drink } \\
\text { "alcopops" } \\
\text { (spirits) }\end{array}$ \\
\hline$\%$ alcohol by volume & 4.00 & 9.00 & 5.00 & 7.50 & 11.00 & 14.00 & 40.00 & 17.50 \\
\hline No of units & 7.0 & 15.8 & 8.8 & 15 & 8.3 & 10.5 & 28 & 12.3 \\
\hline \multicolumn{9}{|l|}{ Implied minimum price } \\
\hline \multicolumn{9}{|l|}{$\begin{array}{l}\text { Under minimum unit } \\
\text { pricing policy proposed } \\
\text { in 2012: }\end{array}$} \\
\hline 40 pence per unit $(£)$ & 2.82 & 6.34 & 3.52 & 6.00 & 3.30 & 4.20 & 11.20 & 4.90 \\
\hline 45 pence per unit $(£)$ & 3.17 & 7.13 & 3.96 & 6.75 & 3.71 & 4.73 & 12.60 & 5.51 \\
\hline 50 pence per unit $(£)$ & 3.52 & 7.92 & 4.40 & 7.50 & 4.13 & 5.25 & 14.00 & 6.13 \\
\hline \multicolumn{9}{|l|}{$\begin{array}{l}\text { Under ban on below } \\
\text { cost selling: }\end{array}$} \\
\hline $\begin{array}{l}\text { Duty+VAT threshold } \\
(£)\end{array}$ & 1.58 & 4.57 & 0.84 & 0.95 & 2.46 & 2.40 & 9.48 & 4.15 \\
\hline $\begin{array}{l}\text { Implied threshold } \\
\text { price per unit (pence) }\end{array}$ & 0.22 & 0.29 & 0.10 & 0.06 & 0.30 & 0.23 & 0.34 & 0.34 \\
\hline
\end{tabular}

VAT=value added tax.

$£ 1.00$ (€1.26; \$1.63); 2014 rates. 
Table 2| Base case estimated own price and cross price elasticities for off-trade and on-trade beer, cider, wine, spirits, and ready to drinks (RTDs, or "alcopops") in the United Kingdom

\begin{tabular}{|c|c|c|c|c|c|c|c|c|c|c|c|}
\hline & & \multicolumn{10}{|c|}{ Purchase } \\
\hline & & Off-beer & Off-cider & Off-wine & Off-spirits & Off-RTDs & On-beer & On-cider & On-wine & On-spirits & On-RTDs \\
\hline \multirow[t]{10}{*}{ Price } & Offt-beer & $-0.980^{\star} \ddagger$ & -0.189 & 0.096 & -0.368 & -1.092 & -0.016 & -0.050 & 0.253 & 0.030 & 0.503 \\
\hline & Off-cider & 0.065 & $-1.268^{\star} \ddagger$ & 0.118 & -0.122 & -0.239 & -0.053 & 0.093 & 0.067 & -0.108 & -0.194 \\
\hline & Off-wine & -0.040 & $0.736^{*}$ & $-0.384^{\star} \ddagger$ & 0.363 & 0.039 & -0.245 & -0.155 & 0.043 & -0.186 & 0.110 \\
\hline & Off-spirits & 0.113 & -0.024 & 0.163 & $-0.082 \ddagger$ & -0.042 & 0.167 & 0.406 & 0.005 & 0.084 & 0.233 \\
\hline & Off-RTDs & -0.047 & -0.159 & -0.006 & 0.079 & $-0.585^{\star} \ddagger$ & -0.061 & 0.067 & 0.068 & $-0.179^{*}$ & 0.093 \\
\hline & Onף-beer & 0.148 & -0.285 & 0.115 & -0.028 & 0.803 & $-0.786^{*} \ddagger$ & 0.867 & $1.042^{*}$ & $1.169^{*}$ & -0.117 \\
\hline & On-cider & -0.100 & 0.071 & 0.043 & 0.021 & 0.365 & 0.035 & $-0.591^{\star} \ddagger$ & 0.072 & $0.237^{*}$ & 0.241 \\
\hline & On-wine & -0.197 & 0.094 & -0.154 & -0.031 & -0.093 & -0.276 & -0.031 & $-0.871^{\star} \ddagger$ & -0.021 & -0.363 \\
\hline & On-spirits & 0.019 & -0.117 & -0.027 & -0.280 & -0.145 & -0.002 & -0.284 & 0.109 & $-0.890^{\star} \ddagger$ & $0.809^{*}$ \\
\hline & On-RTDs & 0.079 & 0.005 & -0.085 & -0.047 & 0.369 & 0.121 & -0.394 & -0.027 & -0.071 & $-0.187 \ddagger$ \\
\hline
\end{tabular}

Each cell gives the estimated percentage reduction in consumption that would occur for the column beverage after a $1 \%$ increase in price for the row beverage. *Significant coefficients at $\mathrm{P}<0.05$.

†Off-beverages are those purchased in off-trade outlets (for example, supermarkets and other shops).

¥Own-price elasticities, with remaining cells showing cross price elasticities.

$\S \rrbracket$ On-beverages are those purchased in on-trade outlets (for example, pubs, clubs, bars, and restaurants). 


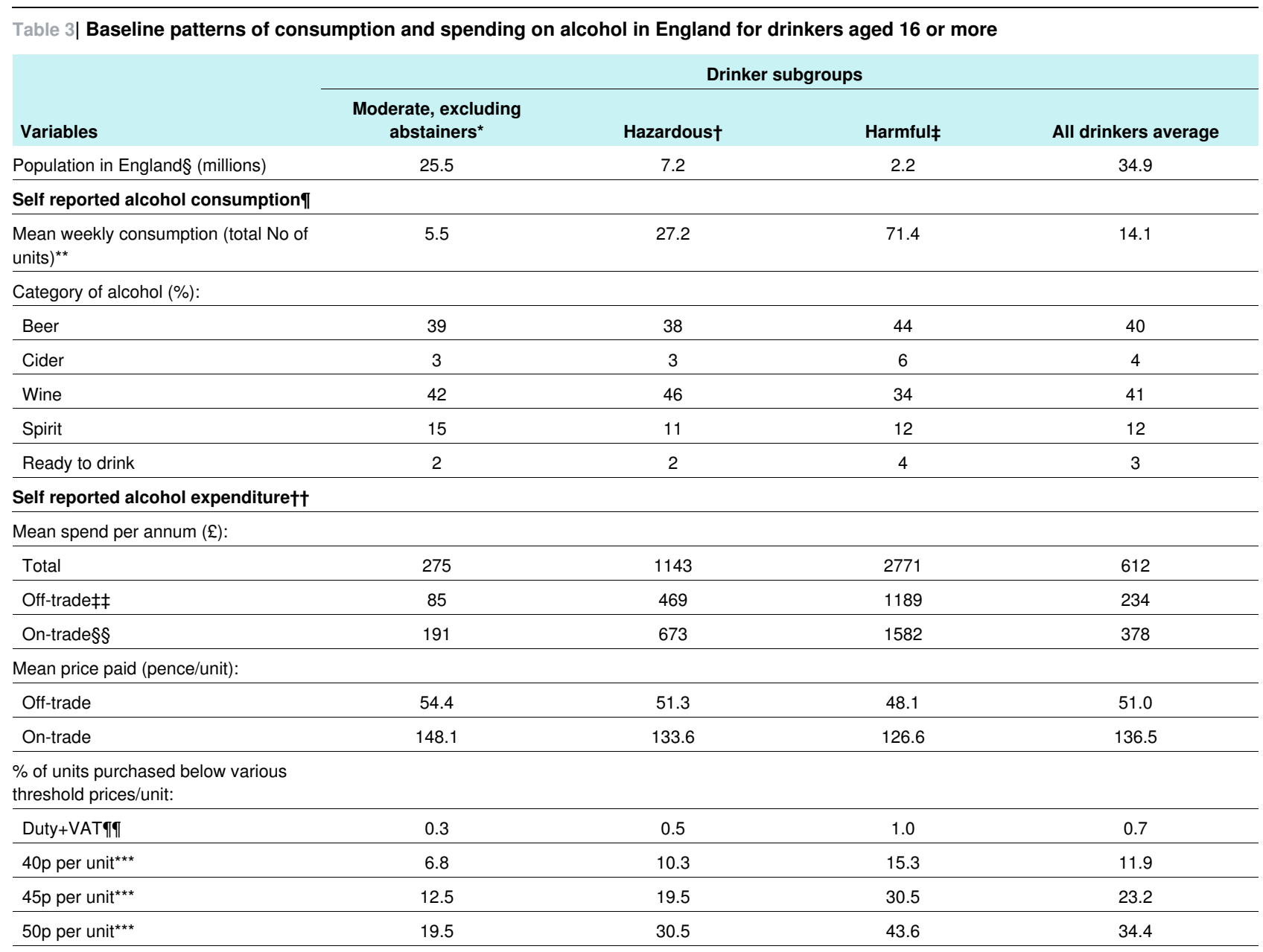

$£ 1.00(€ 1.26 ; \$ 1.63) ; 2014$ rates.

VAT $=$ value added tax.

*Adult drinkers $(\geq 16)$ with a mean weekly consumption $\leq 21$ units for males and $\leq 14$ units for females.

†Mean weekly consumption $>21$ units for males and $>14$ units for females but $\leq 50$ units for males and $\leq 35$ units for females.

$\ddagger$ Mean weekly consumption $>50$ units for males and $>35$ units for females.

§From Office for National Statistics mid-2010 population estimates for England (ages 16-89 inclusive), combined with proportions from general lifestyle survey 2009.

ףFrom general lifestyle survey 2009.

**1 unit=10 $\mathrm{mL}$ by volume of ethanol.

††From living cost and food survey 2001-02 to 2009, inflated to 2013 prices with off-trade interpolated over AC Nielsen price distribution.

$\ddagger \ddagger$ Off-beverages are those purchased in off-trade outlets (for example, supermarkets and other shops).

$\S \S O n$-beverages are those purchased in on-trade outlets (for example, pubs, clubs, bars, and restaurants).

If Estimated in pence per unit of alcohol: 22.9, 9.4, 24.5, 33.9, and 33.9 for beer, cider, wine, spirits, and ready to drinks, respectively in 2013 prices. Details of assumptions are in table 1 of the addendum of the published report. ${ }^{16}$

${ }^{* \star *}$ Minimum unit price thresholds in 2014-15 prices. Details of assumptions can be found in table 2.1 of the published report. ${ }^{13}$ 
Table 4 | Central estimates for consumption and spending for ban on below cost selling and minimum unit price policies of $40 p$, $45 p$, and 50p per unit

Consumption and spending levels Moderate drinkers Hazardous drinkers Harmful drinkers All England population ( $\geq 16$ )

$\%$ change in consumption per drinker

\begin{tabular}{|c|c|c|c|c|}
\hline Below cost selling & -0.03 & -0.01 & -0.08 & -0.04 \\
\hline \multicolumn{5}{|l|}{ Minimum unit price: } \\
\hline $40 p$ & -0.34 & -0.34 & -2.33 & -0.97 \\
\hline $45 p$ & -0.57 & -0.67 & -3.67 & -1.59 \\
\hline $50 p$ & -0.97 & -1.22 & -5.37 & -2.47 \\
\hline \multicolumn{5}{|c|}{ Change in consumption per drinker per year (units) } \\
\hline Below cost selling & -0.1 & -0.1 & -3.0 & -0.3 \\
\hline \multicolumn{5}{|l|}{ Minimum unit price: } \\
\hline $40 p$ & -1.0 & -4.8 & -86.7 & -7.2 \\
\hline $45 p$ & -1.6 & -9.5 & -136.6 & -11.7 \\
\hline $50 p$ & -2.7 & -17.3 & -200.0 & -18.2 \\
\hline \multicolumn{5}{|c|}{$\%$ change in spending per drinker } \\
\hline Below cost selling & 0.00 & 0.03 & 0.01 & 0.02 \\
\hline \multicolumn{5}{|l|}{ Minimum unit price: } \\
\hline $40 p$ & 0.02 & 0.29 & -0.36 & 0.02 \\
\hline $45 p$ & 0.34 & 0.85 & -0.06 & 0.42 \\
\hline $50 p$ & 0.93 & 1.85 & 0.57 & 1.18 \\
\hline \multicolumn{5}{|c|}{ Change in spending per drinker per year $(£)$} \\
\hline Below cost selling & 0.01 & 0.33 & 0.27 & 0.09 \\
\hline \multicolumn{5}{|l|}{ Minimum unit price: } \\
\hline $40 p$ & 0.05 & 3.35 & -9.92 & 0.10 \\
\hline $45 p$ & 0.93 & 9.75 & -1.70 & 2.59 \\
\hline $50 p$ & 2.55 & 21.13 & 15.69 & 7.23 \\
\hline
\end{tabular}

$£ 1.00(€ 1.26 ; \$ 1.63) ; 2014$ rates. 
Table 5 Central estimates of harm reduction for ban on below cost selling and minimum unit price policies of 40p, 45p, and 50p per unit

\begin{tabular}{|c|c|c|c|c|c|c|c|c|c|c|}
\hline \multirow[b]{2}{*}{ Policies } & \multicolumn{4}{|c|}{ Year 1 health harm reductions } & \multicolumn{3}{|c|}{ Year 10 health harm } & \multicolumn{3}{|c|}{ Cumulative health harm } \\
\hline & Deaths & $\begin{array}{l}\text { IIIness } \\
\text { (000s) }\end{array}$ & $\begin{array}{l}\text { Hospital } \\
\text { admissions } \\
\text { (000s) }\end{array}$ & $\begin{array}{l}\text { QALYs } \\
\text { saved } \\
\text { (000s) }\end{array}$ & $\begin{array}{l}\text { Deaths } \\
\text { annually }\end{array}$ & $\begin{array}{l}\text { Illness } \\
\text { annually } \\
\text { (000s) }\end{array}$ & $\begin{array}{l}\text { Hospital } \\
\text { admissions } \\
\text { annually } \\
(000 \mathrm{~s})\end{array}$ & $\begin{array}{c}10 \text { year } \\
\text { cumulative } \\
\text { discounted } \\
\text { QALYs (000s) }\end{array}$ & $\begin{array}{l}10 \text { year } \\
\text { cumulative } \\
\text { healthcare } \\
\text { costs }(£ \mathrm{~m})\end{array}$ & $\begin{array}{c}10 \text { year } \\
\text { financial } \\
\text { valuation of } \\
\text { QALYs ( } \mathrm{Em})\end{array}$ \\
\hline \multicolumn{11}{|c|}{ England population (age $\geq 16$ ) } \\
\hline $\begin{array}{l}\text { Below cost } \\
\text { selling }\end{array}$ & -3 & -0.1 & -0.1 & 0.0 & -14 & -0.3 & -0.5 & 0.5 & -9.5 & 33.0 \\
\hline
\end{tabular}

Minimum unit

price:

\begin{tabular}{|c|c|c|c|c|c|c|c|c|c|c|}
\hline $40 p$ & -74 & -2.4 & -3.5 & 0.8 & -379 & -7.8 & -15.0 & 14.8 & -257.5 & 981.4 \\
\hline $45 p$ & -123 & -4.0 & -5.7 & 1.2 & -624 & -12.5 & -23.7 & 24.2 & -417.2 & 1591.1 \\
\hline $50 p$ & -192 & -6.2 & -8.7 & 1.9 & -960 & -18.7 & -35.1 & 37.1 & -634.2 & 2413.1 \\
\hline \multicolumn{11}{|c|}{ Moderate drinkers } \\
\hline $\begin{array}{l}\text { Below cost } \\
\text { selling }\end{array}$ & -1 & 0.0 & 0.0 & 0.0 & -1 & -0.1 & -0.1 & 0.1 & -2.4 & 8.2 \\
\hline \multicolumn{11}{|c|}{$\begin{array}{l}\text { Minimum unit } \\
\text { price: }\end{array}$} \\
\hline $40 p$ & -10 & -0.4 & -0.5 & 0.2 & -7 & -0.6 & -0.8 & 2.5 & -30.3 & 148.2 \\
\hline $45 p$ & -17 & -0.7 & -0.9 & 0.2 & -11 & -1.0 & -1.4 & 4.1 & -49.5 & 241.5 \\
\hline $50 p$ & -27 & -1.2 & -1.4 & 0.4 & -19 & -1.7 & -2.4 & 6.6 & -82.0 & 388.3 \\
\hline \multicolumn{11}{|c|}{ Hazardous drinkers } \\
\hline $\begin{array}{l}\text { Below cost } \\
\text { selling }\end{array}$ & -1 & 0.0 & 0.0 & 0.0 & -3 & 0.0 & -0.1 & 0.1 & -1.5 & 5.7 \\
\hline \multicolumn{11}{|c|}{$\begin{array}{l}\text { Minimum unit } \\
\text { price: }\end{array}$} \\
\hline $40 p$ & -10 & -0.4 & -0.5 & 0.2 & -23 & -0.5 & -0.8 & 2.0 & -28.2 & 113.8 \\
\hline $45 p$ & -21 & -0.8 & -1.0 & 0.3 & -60 & -1.2 & -1.8 & 3.9 & -58.4 & 227.1 \\
\hline $50 p$ & -39 & -1.5 & -1.8 & 0.5 & -129 & -2.5 & -3.8 & 7.1 & -110.4 & 417.7 \\
\hline \multicolumn{11}{|c|}{ Harmful drinkers } \\
\hline $\begin{array}{l}\text { Below cost } \\
\text { selling }\end{array}$ & -2 & -0.1 & -0.1 & 0.0 & -11 & -0.2 & -0.4 & 0.3 & -5.6 & 19.1 \\
\hline \multicolumn{11}{|c|}{$\begin{array}{l}\text { Minimum unit } \\
\text { price: }\end{array}$} \\
\hline $40 p$ & -53 & -1.6 & -2.4 & 0.4 & -349 & -6.7 & -13.4 & 10.3 & -199.0 & 719.4 \\
\hline $45 p$ & -85 & -2.5 & -3.8 & 0.7 & -554 & -10.3 & -20.5 & 16.2 & -309.4 & 1122.4 \\
\hline $50 p$ & -125 & -3.6 & -5.4 & 1.0 & -812 & -14.5 & -29.0 & 23.4 & -441.8 & 1607.2 \\
\hline
\end{tabular}

QALYs=quality adjusted life years. 


\section{Figures}

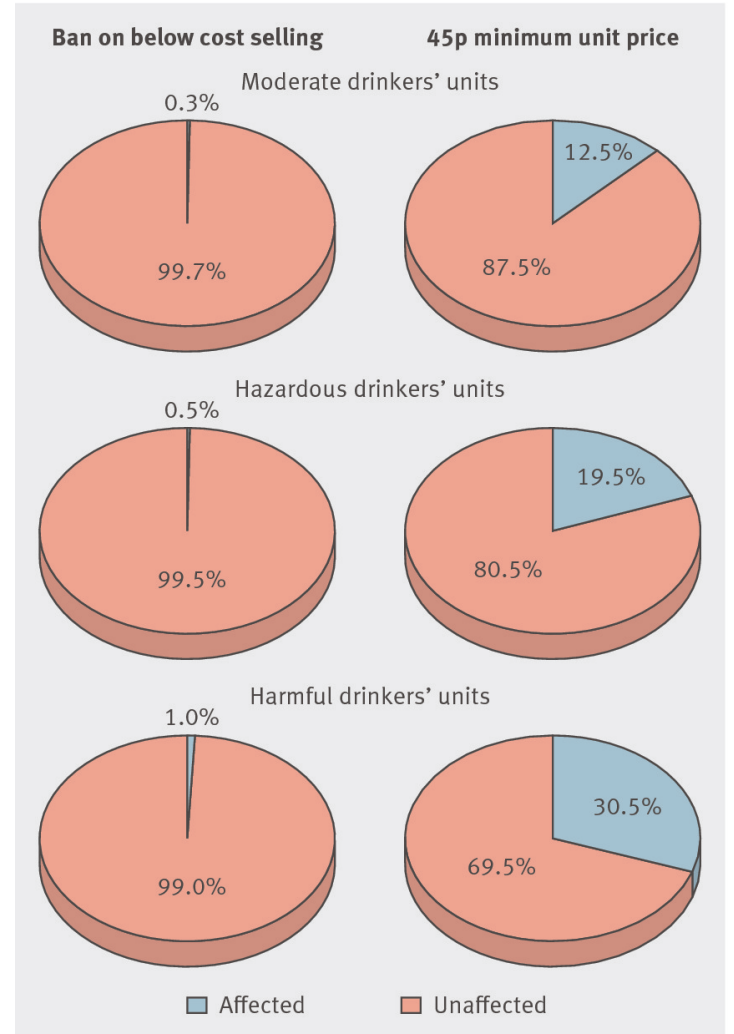

Fig 1 Estimated proportion of current alcohol units consumed that would be affected by price rises from proposed policies of ban on below cost selling versus $45 \mathrm{p}$ minimum unit price central estimate

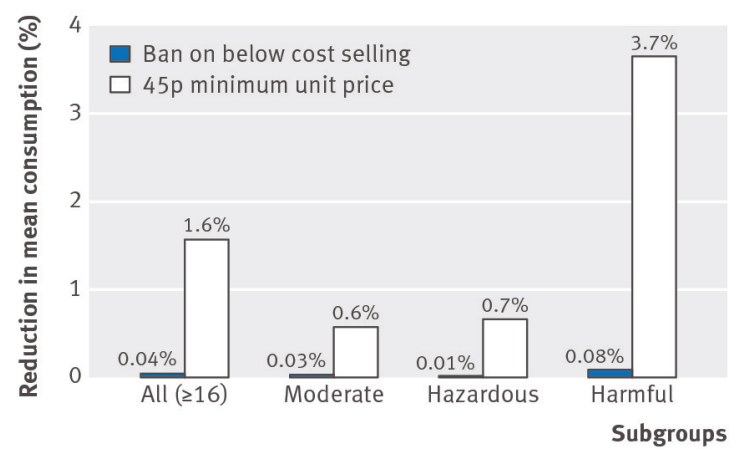

Fig 2 Modelled impact of a ban on below cost selling compared with impact of a 45p minimum unit price 

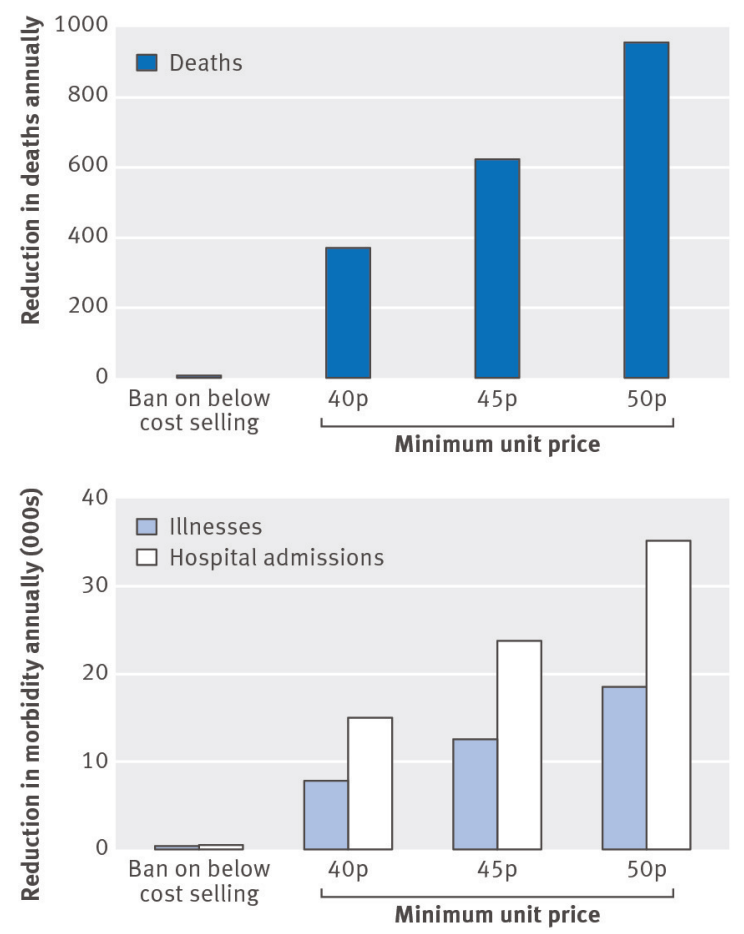

Fig 3 Estimated impact of a ban on below cost selling versus minimum unit price in England in terms of annual savings in deaths, illnesses, and admissions to hospital (at full effect) 